\section{CRYSTAL AND MOLECULAR STRUCTURE OF CLAZAMYCIN A}

Sir :

The crystal structure of clazamycin A hydrochloride has been determined by the X-ray diffraction methods which result in the elucidation of the chemical structure of clazamycins $\mathrm{A}$ and $\mathrm{B}^{1)}$.

The crystals of the hydrochloride were grown as small prisms from a mixed solution of ethanol and ethyl acetate. A crystal with approximate dimensions $0.1 \times 0.2 \times 0.25 \mathrm{~mm}$ was chosen for the X-ray study. The lattice constants were determined from the angular settings for 14 reflections ranging from $2 \theta=50^{\circ}$ to $73^{\circ}$ measured on a Philips PW 1100 diffractometer. Crystal data are shown in Table 1. The intensity data were collected with $\mathrm{CuK} \alpha$ radiation monochromated by a graphite plate using the $\theta-2 \theta$ scan method with a scan speed of $4^{\circ} \min ^{-1}$ in $\theta$. The scans were repeated twice when the tota! counts during the first scan were less than 3,000. The background was counted at each end of the scan for one half of the total scan time. In all 1628 reflections including 378 FRIEDEL pairs of reflections were measured within $2 \theta=156^{\circ}$; of these, 205 were too weak to be measured (below the $2 \sigma(\mathrm{I})$ level) and they were omitted from the intensity data set. The intensities were corrected for Lorentz and polarization factors but no absorption correction was applied.

The crystal structure was solved by the heavy atom method using the two chlorine atoms for the phase determination. The refinement of the structural parameters was carried out by the method of block-diagonal least-squares including anisotropic thermal parameters for individual atoms. Hydrogen atoms were not included. The atomic scattering factors for $\mathrm{C}, \mathrm{N}, \mathrm{O}$ and $\mathrm{Cl}$ atoms, and the correction terms for anomalous dispersion were taken from International Tables for X-ray Crystallography2). The absolute configuration was determined by the anomalous dispersion method. The $\Delta \mathrm{f}^{\prime}$ and $\Delta \mathrm{f}^{\prime \prime}$ terms for the atomic scattering factor for $\mathrm{Cl}$ atoms with $\mathrm{CuK} \alpha$ radiation were taken into account in the structure factor calculations at this stage to give an $\mathrm{R}$ factor of 0.087 (for 1045 reflections). This calculation also clearly established the absolute configuration of the structure. The $\mathrm{R}$ factors for 211 FRIEDEL pairs which showed differences in structure factors between the $\mathrm{hk} l$ and $\overline{\mathrm{h}} \mathrm{k} l$ reflec-

Table 1. Crystal data.

Clazamycin A hydrochloride, $\mathrm{C}_{7} \mathrm{H}_{9} \mathrm{~N}_{2} \mathrm{OCl} \cdot \mathrm{HCl}$, F.W. $=209.1$

orthorhombic, $\mathrm{P} 2{ }_{1} 2_{1} 2_{1}, \mathrm{z}=4, \mathrm{D}_{\mathrm{x}}=1.404 \mathrm{gcm}^{-3}$,

$a=9.138(4), b=16.058(8), c=6.741(3) \AA, U=989.2 \AA^{3}$.

Table 2. Atomic parameters of clazamycin A hydrochloride.

The fractional coordinates $\mathrm{x}, \mathrm{y}$ and $\mathrm{z}$ are multiplied by $10^{4}$. The temperature factor is of the form:

$\mathrm{T}=\exp \left[-\left(\beta_{11} \mathrm{~h}^{2}+\beta_{22} \mathrm{k}^{2}+\beta_{33} l^{2}+2 \beta_{12} \mathrm{hk}+2 \beta_{13} \mathrm{~h} l+2 \beta_{23} \mathrm{k} l\right)\right]$, in which $\beta_{\mathrm{ij}}$ 's are multiplied by $10^{4}$.

\begin{tabular}{l|r|r|r|r|r|r|r|r|r}
\hline & \multicolumn{1}{|c|}{$\mathrm{x}$} & \multicolumn{1}{|c|}{$\mathrm{y}$} & \multicolumn{1}{|c|}{$\mathrm{z}$} & \multicolumn{1}{|c|}{$\beta_{11}$} & \multicolumn{1}{c|}{$\beta_{22}$} & \multicolumn{1}{|c}{$\beta_{33}$} & \multicolumn{1}{c}{$\beta_{12}$} & \multicolumn{1}{|c}{$\beta_{13}$} & \multicolumn{1}{|c}{$\beta_{23}$} \\
\hline C 1 & $7450(6)$ & $1478(5)$ & $4412(11)$ & $91(7)$ & $48(3)$ & $244(16)$ & $-8(4)$ & $3(9)$ & $2(6)$ \\
C 2 & $6875(6)$ & $2010(4)$ & $3103(10)$ & $88(6)$ & $50(3)$ & $235(15)$ & $-5(4)$ & $20(9)$ & $-3(7)$ \\
C 3 & $5282(6)$ & $1914(4)$ & $3168(9)$ & $92(6)$ & $36(2)$ & $197(13)$ & $-2(3)$ & $20(8)$ & $9(6)$ \\
N 3A & $4925(5)$ & $1420(3)$ & $4680(8)$ & $93(5)$ & $34(2)$ & $213(11)$ & $2(3)$ & $11(7)$ & $20(4)$ \\
C 4 & $3700(6)$ & $817(4)$ & $4672(12)$ & $94(7)$ & $40(3)$ & $329(19)$ & $-9(4)$ & $35(10)$ & $22(6)$ \\
C 5 & $4530(8)$ & $-11(5)$ & $4203(13)$ & $121(8)$ & $38(3)$ & $394(23)$ & $-5(4)$ & $3(12)$ & $11(7)$ \\
C 6 & $6022(8)$ & $92(4)$ & $5168(12)$ & $127(8)$ & $42(3)$ & $301(18)$ & $9(4)$ & $-20(12)$ & $0(6)$ \\
C 6A & $6255(6)$ & $1039(4)$ & $5538(10)$ & $98(7)$ & $32(2)$ & $246(16)$ & $3(3)$ & $-7(9)$ & $14(5)$ \\
N 7 & $4359(5)$ & $2278(3)$ & $1931(9)$ & $104(6)$ & $43(2)$ & $239(13)$ & $5(3)$ & $-6(8)$ & $34(5)$ \\
C 8 & $4761(3)$ & $-34(2)$ & $1522(4)$ & $177(3)$ & $76(1)$ & $388(6)$ & $15(2)$ & $-60(4)$ & $-51(3)$ \\
O 9 & $6342(5)$ & $1173(3)$ & $7578(7)$ & $165(7)$ & $49(2)$ & $198(10)$ & $12(3)$ & $-14(7)$ & $14(4)$ \\
Cl 10 & $5923(2)$ & $3072(1)$ & $-1791(2)$ & $104(1)$ & $40(1)$ & $247(3)$ & $2(1)$ & $25(2)$ & $12(1)$ \\
\hline
\end{tabular}


Fig. 1. Chemical structure of clazamycin A.

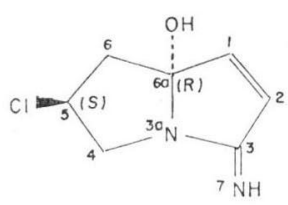

tions of more than $2 \sigma\left(\mathrm{F}_{\mathrm{o}}\right)$, were 0.069 and 0.086 , for the correct set* and inverted set**, respectively. It was also shown that if one takes correct coordinate set, the structure factor ratios, $r_{0}$ and $r_{c}$ between the FrIEDEL pairs, $r_{o}=\left|F_{o}+\right| /\left|F_{o}-\right|$ and $r_{c}=\left|F_{c}+\right| /\left|F_{c}-\right|$, are in good agreement; 185 out of 192 pairs showed the same tendency (if $r_{0}>1$ then $r_{c}>$ 1 or if $r_{o}<1$ then $r_{c}<1$ ). At the final stage of the least-squares refinement, the anomalous scattering effect was taken into account assuming the absolute configuration derived in this way. The weighting system was chosen as: $w=0$ when $F_{o} \leq$ $0.5, w=1$ when $F_{o} \leq 10$ and $\mathrm{W}^{1 / 2}=10 / \mathrm{F}_{\mathrm{o}}$ when $\mathrm{F}_{\mathrm{o}}>10$. The final $\mathrm{R}$ factor was 0.070 for the 1045 observed reflections. The atomic parameters are listed in Table $2 * * *$.

The structure of the molecule determined by the present study is shown in Fig. 1. The configurations of clazamycin A about $\mathrm{C}(6 \mathrm{a})$ and $\mathrm{C}(5)$ are now shown to be $R$ and $S$, respectively. Fig. 2 is a perspective drawing of the molecular structure which also shows bond lengths and
Fig. 2. Molecular structure showing (a) bond lengths $(\AA)$ and (b) bond angles $\left({ }^{\circ}\right)$.
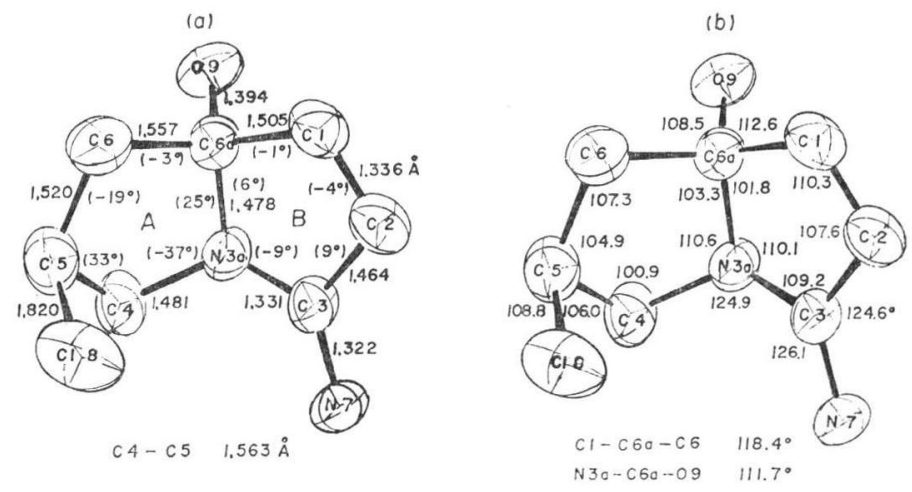

Fig. 3. Crystal structure viewed along the $c$ axis broken lines indicate hydrogen bonds (lengths are in $\AA$ ).

Symmetry operations are: i) $x, y, z$; ii) $-1 / 2+x, 1 / 2-y,-z$; iii) $\mathrm{x}, \mathrm{y},-1+\mathrm{z}$

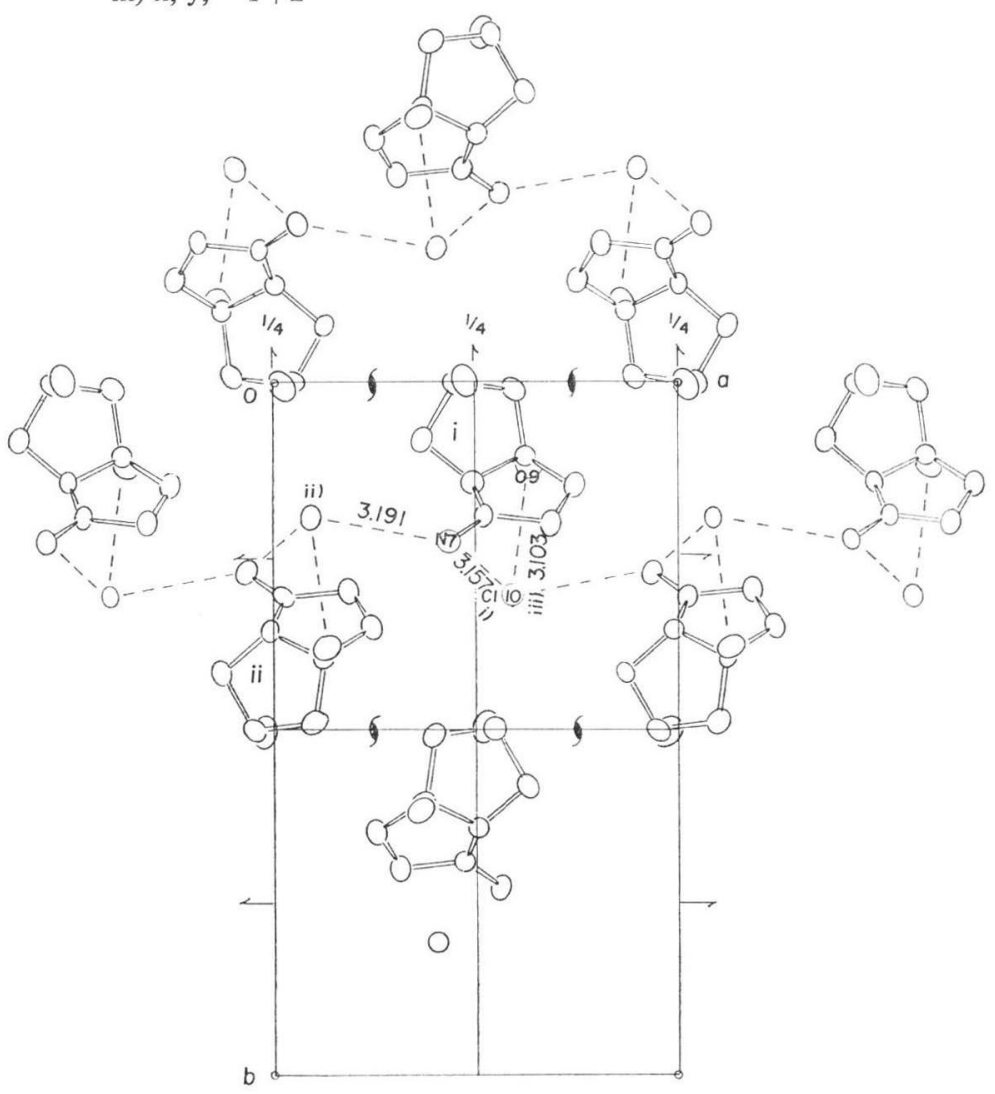

* $\mathrm{R}=\sum \| \mathrm{F}_{\mathrm{o}}+|-| \mathrm{F}_{\mathrm{c}}+|| / \frac{1}{2} \sum\left(\left|\mathrm{F}_{\mathrm{o}}+\right|+\left|\mathrm{F}_{\mathrm{o}}-\right|\right)$

** $\quad \mathrm{R}^{\prime}=\sum|| \mathrm{F}_{\mathrm{o}}+|-| \mathrm{F}_{\mathrm{c}}-|| / \frac{1}{2} \sum\left(\left|\mathrm{F}_{\mathrm{o}}+\right|+\left|\mathrm{F}_{\mathrm{o}}^{-}\right|\right)$where $\mathrm{F}_{\mathrm{o}}{ }^{+}$and $\mathrm{F}_{\mathrm{o}}-$ denote $\mathrm{F}_{\mathrm{o}}(\mathrm{hk} l)$ and $\mathrm{F}_{\mathrm{o}}(\overline{\mathrm{h}} \mathrm{k} l)$ respectively and $\mathrm{F}_{\mathrm{c}}^{+}$and $\mathrm{F}_{\mathrm{c}}-$ denote those for $\mathrm{F}_{\mathrm{c}}$.

*** A list of observed and calculated structure factors may be obtained from the first author upon request. 
angles. The standard deviations of these values are estimated to be: $\sigma(\mathrm{C}-\mathrm{C})=0.009 \AA$ and $\sigma(\mathrm{C}-\mathrm{C}-\mathrm{C})=0.5^{\circ}$. The lengths of the bonds are consistent with the chemical structure. The shortness of the bonds $\mathrm{C}(3)-\mathrm{N}(3 \mathrm{a})$ and $\mathrm{C}(3)-\mathrm{C}$ (2) indicates that the conjugation of the $\mathrm{N}(7)=$ $\mathrm{C}(3)$ double bond extends to $\mathrm{C}(1)$ and $\mathrm{N}(3 \mathrm{a})$. There are no particularly notable lengths and angles involved in the molecule. The conformation of the molecule may be seen from Fig. 2(a) which also shows the end-cyclic torsion angles in rings $\mathrm{A}$ and $\mathrm{B}$. As is clearly seen, ring A possesses a pseudo mirror plane through $\mathrm{C}(4)$ and the mid point of the bond $\mathrm{C}(6 \mathrm{a})-\mathrm{C}(6)$ and takes an envelope form. The flap, atom C(4), deviate by $0.54 \AA$ from the best plane formed by $C(5), C(6), C(6 a), N(3 a)$ in the opposite direction to $\mathrm{Cl}(8)$. The ring $\mathrm{B}$ is planar with an average deviation of $\pm 0.03 \AA$ as expected from the chemical structure but is slightly deformed towards an envelope form. The flap is $\mathrm{C}(3)$ which deviates from the plane through $\mathrm{C}(1), \mathrm{C}(2), \mathrm{C}(3)$, $\mathrm{N}(3 \mathrm{a})$ and $\mathrm{C}(6 \mathrm{a})$ only by $0.05 \AA$ in such a direction that the imino group, $\mathrm{N}(7) \mathrm{H}$, can form hydrogen bonds to $\mathrm{Cl}(10)$ ions. The hydroxyl group $\mathrm{O}(9) \mathrm{H}$ also forms a hydrogen bond to the chloride anion. The intermolecular interactions can be seen in Fig. 3 which show the $c$ axis pro- jection of the crystal structure drawn by the ORTEP program ${ }^{3}$. The molecules are held together along the $a$ axis with the chloride anions forming a chain of hydrogen bonds $-\mathrm{Cl}^{-}-\mathrm{H}-$ $\mathrm{N}(7)-\mathrm{H}-\mathrm{Cl}^{-}-\mathrm{H}-\mathrm{N}(7)-\mathrm{H}-$.

\section{Hikaru Nakamura YoICHI IITAKA}

Faculty of Pharmaceutical Sciences, University of Tokyo, Hongo, Bunkyo-ku, Tokyo 113, Japan

Hamao Umezawa

Institute of Microbial Chemistry, Kamiosaki, Shinagawa-ku, Tokyo, 141, Japan

(Received May 11, 1979)

\section{References}

1) Horiuchi, Y.; S. Kondo, T. IKedA, D. IKedA, K. Miura, M. Hamada, T. Takeuchi \& H. UMEZAWA: New antibiotics, clazamycins A and B. J. Antibiotics 32: 762 764, 1979

2) "International Tables for X-ray Crystallography. Vol. IV", pp. 72 98, Kynoch Press, Birmingham, 1974

3) JoHnson, C. K.: ORTEP, Report ORNL-3794, Oak Ridge National Laboratory, Oak Ridge, Tennessee, U.S.A., 1965 